\title{
Expanding the Neuroimaging Phenotype of Neuronal Ceroid Lipofuscinoses
}

\author{
(D) A. Biswas, (D). Krishnan, (D)A. Amirabadi, (D). Blaser, (D). Mercimek-Andrews, and (DM. Shroff
}

\begin{abstract}
BACKGROUND AND PURPOSE: Neuronal ceroid lipofuscinoses are a group of neurodegenerative disorders characterized by the accumulation of autofluorescent lipopigments in neuronal cells. As a result of storage material in the brain and retina, clinical manifestations include speech delay, cognitive dysfunction, motor regression, epilepsy, vision loss, and early death. At present, 14 different ceroid lipofuscinosis (CLN) genes are known. Recently, the FDA approved the use of recombinant human proenzyme of tripeptidyl-peptidase 1 for CLN2 disease, while phase I/lla clinical trials for gene therapy in CLN3 and CLN6 are ongoing. Early diagnosis is, therefore, key to initiating treatment and arresting disease progression. Neuroimaging features of CLN1, CLN2, CLN3, and CLN5 diseases are well-described, with sparse literature on other subtypes. We aimed to investigate and expand the MR imaging features of genetically proved neuronal ceroid lipofuscinoses subtypes at our institution and also to report the time interval between the age of disease onset and the diagnosis of neuronal ceroid lipofuscinoses.
\end{abstract}

MATERIALS AND METHODS: We investigated and analyzed the age of disease onset and neuroimaging findings (signal intensity in periventricular, deep, and subcortical white matter, thalami, basal ganglia, posterior limb of the internal capsule, insular/subinsular regions, and ventral pons; and the presence or absence of supratentorial and/or infratentorial atrophy) of patients with genetically proved neuronal ceroid lipofuscinoses at our institution. This group consisted of 24 patients who underwent 40 brain MR imaging investigations between 1993 and 2019, with a male preponderance (male/female ratio $=15: 9$ ).

RESULTS: The mean ages of disease onset, first brain MR imaging, and diagnosis of neuronal ceroid lipofuscinoses were $4.70 \pm 3.48$ years, $6.76 \pm 4.49$ years, and $7.27 \pm 4.78$ years, respectively. Findings on initial brain MR imaging included T2/FLAIR hypointensity in the thalami ( $n=22)$; T2/FLAIR hyperintensity in the periventricular and deep white matter $(n=22)$, posterior limb of the internal capsule $(n=22)$, ventral pons $(n=19)$, and insular/subinsular region $(n=18)$; supratentorial $(n=21)$ and infratentorial atrophy $(n=20)$. Eight of 9 patients who had follow-up neuroimaging showed progressive changes.

CONCLUSIONS: We identified reported classic neuroimaging features in all except 1 patient with neuronal ceroid lipofuscinoses in our study. CLN2, CLN5, and CLN7 diseases showed predominant cerebellar-over-cerebral atrophy. We demonstrate that abnormal signal intensity in the deep white matter, posterior limb of the internal capsule, and ventral pons is more common than previously reported in the literature. We report abnormal signal intensity in the insular/subinsular region for the first time. The difference in the median time from disease onset and diagnosis was 1.5 years.

ABBREVIATIONS: $\mathrm{CLN}=$ ceroid lipofuscinosis; DWM = deep white matter; $\mathrm{IQR}=$ interquartile range; I-SI $=$ insular/subinsular region; $\mathrm{NCL}=$ neuronal ceroid lipofuscinoses; PLIC = posterior limb of the internal capsule; PVWM = periventricular white matter; SCWM = subcortical white matter

$\mathrm{N}$ euronal ceroid lipofuscinoses (NCL) are a group of clinically and genetically heterogeneous lysosomal storage disorders characterized by the accumulation of autofluorescent lipopigments in neuronal cells of the brain and retina. ${ }^{1}$ They constitute

Received May 2, 2020; accepted after revision June 16.

From the Department of Diagnostic Imaging (A.B., P.K., A.A., S.B., M.S.), The Hospital for Sick Children, Toronto, Canada; Division of Clinical and Metabolic Genetics (S.M.-A.), Department of Pediatrics, University of Toronto, The Hospital for Sick Children, Toronto, Canada.

Previously presented in poster format at: Annual Meeting of the American Society of Pediatric Neuroradiology, January 10-12, 2020; Miami Beach, Florida. the most common neurodegenerative disorders of childhood, with an estimated incidence of 1.6-2.4/100,000 in the United States, 2.2/100,000 in Sweden, 2-2.5/100,000 in Denmark, 3.9/ 100,000 in Norway, 4.8/100,000 in Finland, and 7/100,000 in Iceland. ${ }^{1,2}$ Clinical manifestations include speech delay, cognitive

Please address correspondence to Asthik Biswas, MD, MBBS, Department of Diagnostic Imaging, The Hospital for Sick Children, 555 University Ave, Toronto, ON, M5G 1X8, Canada; e-mail: asthik.biswas@sickkids; caasthikbiswas@gmail.com; @stikkman11

http://dx.doi.org/10.3174/ajnr.A6726 
Table 1: Subgroups of NCL, their genes, protein names, and MIM numbers

\begin{tabular}{lllr}
\hline Locus Name & Gene Symbol & \multicolumn{1}{c}{ Protein Name } & MIM Number \\
\hline CLN1 & PPT1 & Palmitoyl protein thioesterase 1 & 600722 \\
CLN2 & TPP1 & Tripeptidyl peptidase 1 & 607998 \\
CLN3 & CLN3 & CLN3 & 607042 \\
CLN4 & DNAJC5 & Dnaj homolog & 611203 \\
CLN5 & CLN5 & CLN5 & 608102 \\
CLN6 & CLN6 & CLN6 & 601780 \\
CLN7 & MFSD8 & Major facilitator superfamily & 611124 \\
CLN8 & CLN8 & CLN8 & 607837 \\
CLN9 & N/A & Unknown & 609055 \\
CLN10 & CTSD & Cathepsin D & 116840 \\
CLN11 & GRN & Granulins & 138945 \\
CLN12 & ATP13A2 & Probable cation transporting & 610513 \\
CLN13 & CTSF & Cathepsin F & 603539 \\
CLN14 & KCTD7 & BTB/POZ domain-containing & 611725 \\
\hline
\end{tabular}

Note:-MIM indicates Mendelian Inheritance in Man; N/A, not applicable.

\section{Age of onset, first MRI and diagnosis}

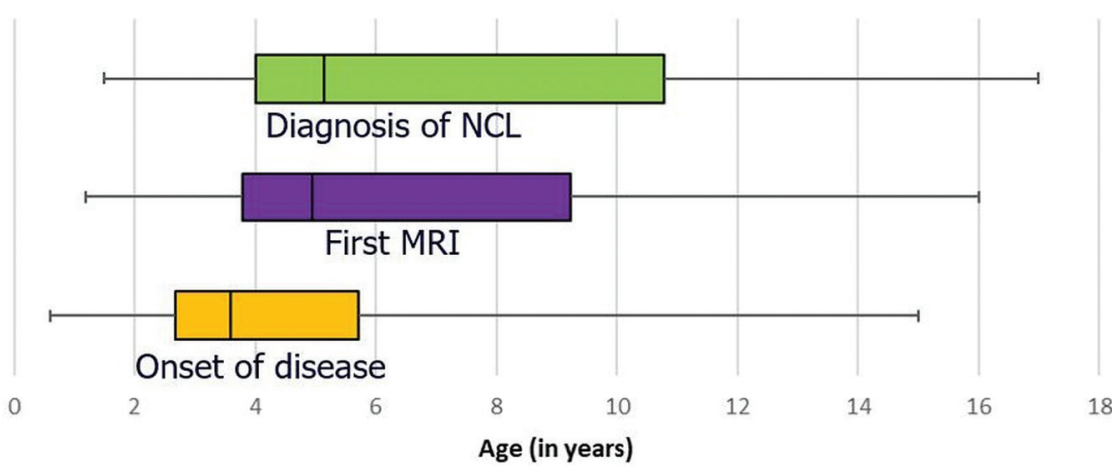

FIG 1. Time delay between disease onset (median, 3.6 years; IQR, 3 years) and clinical, radiologic, and histopathologic diagnoses (median, 5.1 years; IQR, 6.7 years) of NCL is depicted. diseases, ${ }^{20-25}$ with scarce literature on other subtypes. ${ }^{26-31}$ Given the rapidly changing landscape in cell biology and translation in NCL and the need for early diagnosis facilitating early treatment, we performed a retrospective review study to investigate and expand the MR imaging features of the disease in patients with genetically confirmed NCL diagnosed at our institution. We also report the time interval between the age of disease onset, first brain MR imaging, and diagnosis in this study.

\section{MATERIALS AND METHODS}

The institutional Research Ethics Board approved the study (REB 1000065260). Patients were identified from a previous study data base. ${ }^{32}$ Patient demographics and clinical features were obtained through electronic chart review. Brain MR imaging examinations were reviewed for quality and co-read by 2 of the authors (A.B. and P.K.) with consensus review. Specifically, the nature of T2 signal intensity in the thalami, periventricular white matter (PVWM), deep white matter (DWM), subcortical white matter (SCWM), basal ganglia, posterior limb of the internal capsule (PLIC), insular/subinsular region (ISI), and ventral pons, along with the presence or absence of supratentorial dysfunction, developmental regression, epilepsy, vision loss, and early death. ${ }^{3}$ Although traditionally classified on the basis of the age of onset (infantile, late-infantile, juvenile, and adult), classification is now based on genetic etiology, with 14 different ceroid lipofuscinosis (CLN) genes known at present (Table 1). ${ }^{4}$ Several new insights into the cell biology of NCL have emerged, ${ }^{5-7}$ with ongoing translational research likely to have therapeutic implications. ${ }^{8}$ Furthermore, it has been proposed that the different subtypes of NCL are actually distinct disorders, each with a unique underlying molecular pathomechanism sharing a common end point in the form of neuronal loss and autofluorescent storage material. ${ }^{8}$ Recently, the FDA approved the use of cerliponase alfa (Brineura), a recombinant human proenzyme of tripeptidyl-peptidase 1, for CLN2 disease. ${ }^{9}$ The treatment arrests disease progression; therefore, early diagnosis is essential for optimal treatment outcomes. In addition, phase I/IIa clinical trials with gene therapy are currently in progress for CLN $3^{10}$ and CLN6 diseases. ${ }^{11}$

The classic neuroimaging features in brain MR imaging of NCL reported in the literature include T2-hypointense thalami, T2-hyperintense periventricular white matter, and progressive cerebral and cerebellar volume loss. ${ }^{12-19}$ Subtype-specific imaging findings are well-described in CLN1, CLN2, CLN3, and CLN5 and infratentorial atrophy, was documented. Atrophy was graded subjectively as mild, moderate, and severe. Note was made of the degree of cerebral atrophy relative to cerebellar atrophy. Volumetric analysis was not performed due to insufficient numbers of cases with volume data. The age of disease onset was determined by documented history in the hospital records system (Chartmaxx; https://chartmaxx.software.informer.com/). A working diagnosis of NCL was defined either by a histopathologic basis with positive conjunctival or skin biopsy demonstrating curvilinear profiles, fingerprint profiles, or granular osmiophilic profiles; or by a clinicoradiologic basis when clinical presentation or family history, or both in conjunction with MR imaging findings were highly suggestive of the diagnosis. All patients in the cohort eventually had confirmed genetic diagnoses via direct Sanger testing, the details of which have been published previously. ${ }^{32}$ Data were entered into Excel (Microsoft). Data were analyzed with descriptive statistics (median and interquartile range [IQR] for age calculated in Excel).

\section{RESULTS}

Thirty-four patients with genetically confirmed neuronal ceroid lipofuscinosis were identified between 1993 and 2019. Most of these patients and their molecular genetic investigations have 


\begin{tabular}{|c|c|c|c|c|c|c|c|}
\hline NCL Subtypes & Sex & $\begin{array}{l}\text { Speech } \\
\text { Delay } \\
n(\%)\end{array}$ & $\begin{array}{c}\text { Visual } \\
\text { Impairment } \\
n(\%)\end{array}$ & $\begin{array}{c}\text { Seizures } \\
n(\%)\end{array}$ & $\begin{array}{c}\text { Behavioral } \\
\text { Abnormalities } \\
n(\%)\end{array}$ & $\begin{array}{l}\text { Cognitive } \\
\text { Decline } \\
n(\%)\end{array}$ & $\begin{array}{l}\text { Developmental } \\
\text { Regression } n(\%)\end{array}$ \\
\hline CLN1 disease $(n=6)$ & $\mathrm{M}(n=4), \mathrm{F}(n=2)$ & $5(83)$ & $5(83)$ & $4(67)$ & $3(50)$ & $5(83)$ & $5(83)$ \\
\hline CLN2 disease $(n=5)$ & $M(n=5)$ & $4(80)$ & $3(60)$ & $4(80)$ & $2(40)$ & $4(80)$ & $4(80)$ \\
\hline CLN3 disease $(n=2)$ & $M(n=2)$ & $2(100)$ & $2(100)$ & $1(50)$ & $2(100)$ & $2(100)$ & $2(100)$ \\
\hline CLN5 disease $(n=1)$ & $\mathrm{F}(n=1)$ & $1(100)$ & $1(100)$ & $1(100)$ & $1(100)$ & $1(100)$ & $1(100)$ \\
\hline CLN6 disease $(n=2)$ & $\mathrm{M}(n=1), \mathrm{F}(n=1)$ & $1(50)$ & $1(50)$ & $1(50)$ & $1(50)$ & $2(100)$ & $2(100)$ \\
\hline CLN7 disease $(n=6)$ & $\mathrm{M}(n=4), \mathrm{F}(n=2)$ & $6(100)$ & $2(33)$ & $6(100)$ & $2(33)$ & $6(100)$ & $6(100)$ \\
\hline CLN8 disease $(n=2)$ & $\mathrm{M}(\mathrm{n}=1), \mathrm{F}(n=1)$ & $2(100)$ & $0(0)$ & $2(100)$ & $0(0)$ & $2(100)$ & $2(100)$ \\
\hline
\end{tabular}

${ }^{a}$ Data are number of patients (percentage in parenthesis).

Table 3: Brain MR imaging features of patients with NCL

\begin{tabular}{|c|c|c|c|c|c|c|c|}
\hline \multirow[b]{2}{*}{ NCL Subtypes } & \multirow[b]{2}{*}{$\begin{array}{l}\text { T2 hypointense } \\
\text { thalami } n(\%)\end{array}$} & \multicolumn{4}{|c|}{ T2 Hyperintensity $\mathrm{n}(\%)$} & \multicolumn{2}{|c|}{ Volume Loss n (\%) } \\
\hline & & $\begin{array}{l}\text { Corpus } \\
\text { Striatum }\end{array}$ & $\begin{array}{c}\text { STWM (PVWM and/or } \\
\text { DWM and/or SCWM } \\
\text { and/or PLIC) }\end{array}$ & $\begin{array}{c}\text { Insular/Sub- } \\
\text { Insular }\end{array}$ & Pons & Supratentorial & Cerebellar \\
\hline CLN1 disease $(n=6)$ & $6(100)$ & $6(100)$ & $6(100)$ & $4(67)$ & $6(100)$ & $6(100)$ & $6(100)$ \\
\hline CLN2 disease $(n=5)$ & $5(100)$ & $3(60)$ & $5(100)$ & $4(80)$ & $3(60)$ & $4(80)$ & $4(80)$ \\
\hline CLN3 disease $(n=2)$ & $0(0)$ & $0(0)$ & $1(50)$ & $1(50)$ & $0(0)$ & $2(100)$ & $0(0)$ \\
\hline CLN5 disease $(n=1)$ & $1(100)$ & $1(100)$ & $1(100)$ & $1(100)$ & $1(100)$ & $1(100)$ & $1(100)$ \\
\hline CLN6 disease $(n=2)$ & $2(100)$ & $1(50)$ & $2(100)$ & $1(50)$ & $2(100)$ & $1(50)$ & $1(50)$ \\
\hline CLN7 disease $(n=6)$ & $6(100)$ & $2(33)$ & $6(100)$ & $5(83)$ & $5(83)$ & $5(83)$ & $6(100)$ \\
\hline CLN8 disease $(n=2)$ & $2(100)$ & $2(100)$ & $2(100)$ & $2(100)$ & $2(100)$ & $2(100)$ & $2(100)$ \\
\hline
\end{tabular}

Note:-STWM indicates supratentorial white matter.

been reported. ${ }^{32}$ Of these, 24 patients (male/female ratio $=15: 9$ ) had $40 \mathrm{MR}$ imaging examinations and were therefore included in the study. The time delay between disease onset and diagnoses is depicted in Fig 1. The median (IQR) age of disease onset, first brain MR imaging, and age of genetic diagnoses were 3.6 (3.0), 4.9 (5.4), and 5.1 (6.7) years, respectively (Fig 1). The NCL subtypes were CLN1 $(n=6)$, CLN2 $(n=5)$, CLN3 $(n=2)$, CLN5 $(n=1)$, CLN6 $(n=2)$, CLN7 $(n=6)$, and CLN8 $(n=2)$ diseases. The most common symptom was developmental and cognitive regression $(n=22)$. Other presenting symptoms included speech delay $(n=21)$, seizures $(n=19)$, impaired vision $(n=14)$, and behavioral abnormalities $(n=11)$. Clinical features and their distribution to each subgroup of NCL are listed in Table 2.

Brain MR imaging features are summarized in Table 3. Findings on initial brain MR imaging included the following: 1) T2/FLAIR hypointensity in the thalami $(n=22) ; 2)$ T2/FLAIR hyperintensity in the PVWM and DWM $(n=22) ; 3)$ T2/FLAIR hyperintensity in the PLIC $(n=22) ; 4)$ T2/FLAIR hyperintensity in the ventral pons $(n=19) ; 5)$ T2/FLAIR hyperintensity in the I-SI region $(n=18) ; 6)$ supratentorial atrophy $(n=21$; mild, $[n=10]$; moderate-severe, $[n=11]$; and 7) cerebellar atrophy $[n=20])$. Eight of 9 patients who had follow-up neuroimaging showed progressive changes. Imaging findings in each subtype are summarized below.

\section{CLN1 Disease}

In CLN1 disease $(n=6)$, the median (IQR) age of onset was 3 (8.5) years, while the median (IQR) age at first MR imaging was 3.5 (11.5) years. On the initial MR imaging, all patients $(n=6)$ showed T2/FLAIR hypointensity in the thalami and T2 hyperintensity in the basal ganglia. All patients had T2/FLAIR hyperintensity in the PVWM, DWM, PLIC, and pons, while only 1 patient showed abnormality in the SCWM. Four patients demonstrated T2/FLAIR hyperintensity in the I-SI region. All patients showed supratentorial atrophy $($ mild $=2$; moderate $=2$; severe $=$ 2 ) and cerebellar atrophy (mild $=4$; moderate $=2$ ), with 5 patients showing brain stem atrophy. In all 6 patients, the degree of cerebral atrophy was greater than that of cerebellar atrophy.

Three of 6 patients had follow-up imaging. All 3 patients demonstrated progressive supratentorial and cerebellar volume loss, and 2 patients showed progressive white matter T2/FLAIR hyperintensity now extending to involve the SCWM.

\section{CLN2 Disease}

In CLN2 disease $(n=5)$, the median (IQR) age of onset was 3.5 (5.3) years. The median (IQR) age the first MR imaging was 8.7 (8.4) years. All patients $(n=5)$ showed T2/FLAIR hypointensity in the thalami, whereas 3 patients showed T2 hyperintensity in basal ganglia. All patients showed T2/FLAIR hyperintensity in the PLIC, PVWM, and DWM, with 1 patient demonstrating abnormality involving the SCWM. Four patients showed T2/FLAIR hyperintensity in the I-SI region, and 3 showed signal abnormality in the pons.

Four patients showed supratentorial atrophy $($ mild $=1$; moderate $=1$; severe $=2$ ) and cerebellar atrophy (mild $=2$; severe $=2$ ), with 4 patients showing brain stem atrophy. In 3 of 5 patients, cerebellar atrophy was greater than cerebral atrophy.

Three patients had follow-up imaging. All 3 showed progressive supratentorial atrophy, and 2 showed progression in cerebellar atrophy. One patient who had normal signal in the I-SI region and pons on the initial MR imaging showed signal abnormality in both regions on follow-up MR imaging. 


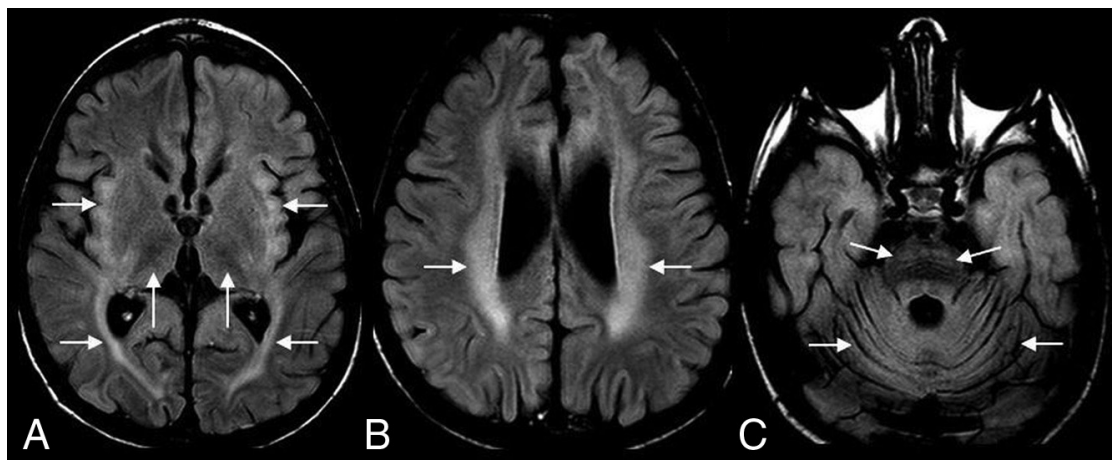

FIG 2. A 4-year-old boy with CLN2 disease. Axial FLAIR MR imaging shows hypointense thalami and hyperintense insular/subinsular region and posterior limb of the internal capsule $(A)$; hyperintense periventricular and deep white matter $(B)$, and hyperintense ventral pons $(C)$. Note diffuse cerebral and cerebellar volume loss $(A-C)$.

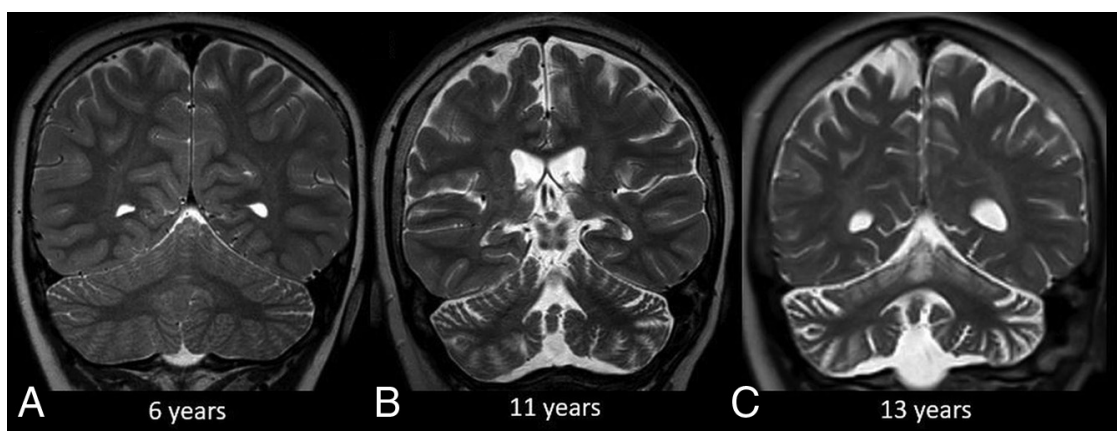

FIG 3. Progression of CLN2 disease. Coronal T2-weighted MR imaging at 6 years of age $(A)$ shows no discernible volume loss. Follow-up MR imaging at 11 and 13 years of age ( $B$ and $C$ ) shows progressive cerebral and cerebellar volume loss. Note the greater degree of cerebellar volume loss relative to the cerebrum.

Sample cases of CLN2 disease are shown in Figs 2 and 3.

\section{CLN3 Disease}

In CLN3 disease $(n=2)$, the age of onset was 10 years in patient $3 \mathrm{~A}$ and was unknown in patient $3 \mathrm{~B}$. MR imaging of patient $3 \mathrm{~A}$ performed at 6 years of age showed no signal abnormality or volume loss on the initial MR imaging. Follow-up MR imaging at 10 years of age showed supratentorial volume loss with PVWM and DWM signal abnormality. MR imaging of patient 3B performed at 1.2 years of age showed only mild supratentorial atrophy without signal change and no obvious progression on followup imaging after 6 years (the first MR imaging for patient $3 \mathrm{~B}$ was actually performed for follow-up of intraventricular hemorrhage; therefore, the atrophy was possibly not related to NCL). Neither patient had cerebellar atrophy.

\section{CLN5 Disease}

In CLN5 disease $(n=1)$, the disease onset was at 3.5 years of age. MR imaging at 6.5 years of age showed T2/FLAIR hypointense thalami; and T2/FLAIR hyperintensity in basal ganglia, PVWM, DWM, PLIC, I-SI region, and pons, along with mild supratentorial and severe cerebellar atrophy. There was no follow-up MR imaging.

\section{CLN6 Disease}

In CLN6 disease $(n=2)$, the age at disease onset was 4 years in a female and 9 years in a male patient. MR imaging of both patients (6A and $6 \mathrm{~B}$, at 8.6 years and 10.8 years of age) showed T2/FLAIR hypointense thalami, and both showed T2/FLAIR hyperintense signal in the PLIC, PVWM, DWM, and pons (none in the SCWM). One (patient 6A) had T2/FLAIR hyperintensity in the basal ganglia. Patient 6A showed severe supratentorial and cerebellar atrophy and brain stem atrophy. Patient 6B did not have atrophy on the initial MR imaging but showed mild supratentorial atrophy on follow-up imaging after 4.5 years. Both patients showed a greater degree of cerebral atrophy compared with cerebellar atrophy.

\section{CLN7 Disease}

In CLN7 disease $(n=6)$, the median age of onset of disease was 3.75 years (IQR, 3.1 years), while the median age at first MR imaging was 4.5 years (IQR, 4 years). All patients showed T2/FLAIR hypointense thalami; 2 showed a T2/FLAIR hyperintense basal ganglia; all showed T2/FLAIR hyperintense PLIC, PVWM, and DWM (none in the SCWM) and 5 showed abnormal signal in the I-SI region and pons. Five patients showed supratentorial atrophy $($ mild $=3$; moderate $=2)$, while all 6 patients showed cerebellar atrophy $($ mild $=1$; moderate $=4$; severe $=1)$. Four patients had brain stem atrophy. In 5 of 6 patients, the degree of cerebellar atrophy was greater than cerebral atrophy (Fig 4), with equal atrophy in 1 patient. None of the patients had follow-up MR imaging.

\section{CLN8 Disease}

In CLN8 disease $(n=2)$, the age of disease onset was 3.7 years in a male $(8 \mathrm{~A})$ and 3.3 years in a female $(8 \mathrm{~B})$ patient. MR imaging of both patients (at 4.5 and 3.3 years, respectively) showed T2/ FLAIR hypointense thalami and T2/FLAIR hyperintense basal ganglia, PVWM, DWM, PLIC, I-SI region, and pons. None had SCWM signal abnormality. Both showed supratentorial (mild = 1 ; moderate $=1$ ) and cerebellar $($ mild $=1$, moderate $=1$ ) atrophy. Patient $8 \mathrm{~A}$ had greater cerebellar atrophy compared with cerebral atrophy while patient $8 \mathrm{~B}$ had an equal degree of atrophy. Neither of the patients had follow-up MR imaging.

\section{DISCUSSION}

We report 24 patients with genetically confirmed NCL and their brain MR imaging features, which is one of the largest patient 


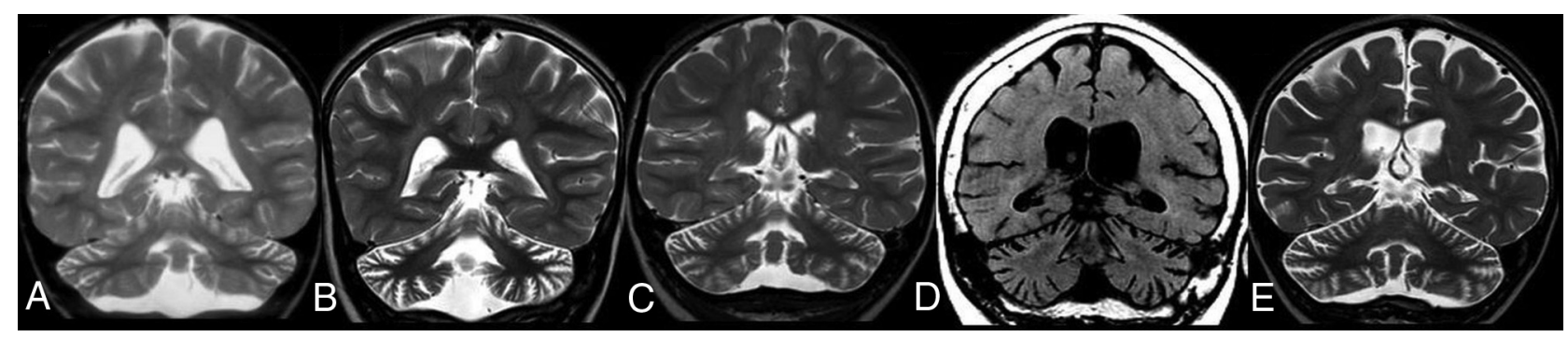

FIG 4. CLN7 disease. Coronal T2-weighted MR imaging of 4 different patients $(A, B, C$, and $E)$ and coronal reformatted $C T$ of 1 patient (D). Note cerebellar more than cerebral volume loss in all patients.

cohorts, to the best of our knowledge. Brain MR imaging findings of atrophy and white matter signal changes in NCL were first reported by Machen et al, ${ }^{33}$ expanding the findings on previously reported brain MR imaging features of NCL on CT. ${ }^{34}$ To the best of our knowledge, thalamic T2 hypointensity and periventricular T2 hyperintense rims in infantile-onset NCL were reported by Vanhanen et $\mathrm{al}^{35}$ for the first time in 1994. The white matter signal change was hypothesized to represent loss of myelin due to Wallerian degeneration based on histopathologic and microscopic studies. ${ }^{7,36-38}$ The thalamic T2 darkening was speculated to represent accumulation of iron, though this was debated. ${ }^{38}$ Vanhanen et $\mathrm{al}^{14}$ studied postmortem MR imaging with histopathologic correlation in 8 patients with infantile NCL in 1995 and demonstrated almost complete loss of cortical neurons, axons, and myelin sheaths in all patients, along with astrocytic proliferation containing periodic-acid-Schiff-positive storage material. They also demonstrated loss of thalamic neurons and loss of granular and Purkinje cells in the cerebellar cortex. They speculated that the thalamic T2 hypointense signal was due to accumulation of saposin (similar to GM2 gangliosides) and also by hypertrophic astrocytes containing storage protein and glial fibrillary acid protein.

In addition to their previous reports, Vanhanen et al, ${ }^{18}$ in 1995, reported progressive cerebral atrophy in infantile-onset NCL starting from 13 months of age and peaking at 4 years of age, redemonstrated by the same group in 2004 in patients with proved CLN1, ${ }^{20}$ with cerebellar atrophy lagging behind cerebral atrophy. All 6 of our patients with CLN1 disease (infantile onset) showed this pattern of initial early-onset cerebral atrophy followed by later-onset cerebellar atrophy.

Patients with late infantile-onset NCL have been reported to show early-onset cerebellar atrophy. ${ }^{23,39,40}$ We also identified similar findings in our late-infantile-onset CLN2, CLN5, and CLN7 diseases, wherein most patients showed earlier onset and, in most, a greater degree of cerebellar atrophy compared with cerebral atrophy. Interestingly, this was most remarkable in our CLN7 disease cohort wherein 5 of 6 patients showed this finding. On the other hand, both patients with CLN6 disease (early-juvenile and late-infantile NCL) had a greater degree of cerebral atrophy compared with cerebellar atrophy.

Juvenile NCL generally demonstrates cerebral and cerebellar atrophy, usually after the ages of 9 and 13 years respectively, ${ }^{19}$ though quantitative white matter signal intensities may be abnormal at a younger age. ${ }^{19}$ Studies have also demonstrated progressive hippocampal atrophy, ${ }^{25}$ altered white matter microstructure, ${ }^{22}$ and decreased volume of the dorsomedial thalami and corona radiata in CLN3 disease. ${ }^{24}$ One of our patients (3A) with CLN3 disease had mild PVWM and DWM signal abnormality and mild supratentorial volume loss at 14 years of age, while the other patient (3B) was only imaged up to 7 years of age and had no discernible signal abnormality. Unfortunately, we do not have morphometric data on these images.

White matter signal abnormalities, starting from the periventricular white matter with progression to deep and subcortical white matter in NCL, have been reported and have been attributed to white matter degeneration or abnormal myelin. ${ }^{18,19}$ We noted a distinctive abnormality in our cohort with involvement of the insular/subinsular region seen in $75 \%$ of our patients. To the best of our knowledge, this brain MR imaging feature has not been reported previously. Additionally, we identified T2/FLAIR hyperintensity of the PLIC and ventral pons in $91 \%$ and $79 \%$, respectively, in our study cohort, which has been rarely reported in the literature. ${ }^{17,18}$ Jadav et $\mathrm{al}^{17}$ reported PLIC hyperintensity as an uncommon-but-characteristic brain MR imaging feature of CLN3 disease, though Holmberg et $\mathrm{al}^{23}$ also had previously reported this finding in a CLN5 disease cohort. In our study, this was seen not only in juvenile-onset but also in infantile and lateinfantile onset NCL.

The differences in imaging phenotypes (eg, predominant cerebral over cerebellar atrophy and vice versa) is intriguing. As alluded to earlier, different subtypes of NCL may represent distinct disorders, each with its own molecular pathway converging to a common end point (including storage of autofluorescent material and neuronal death). The NCL genes encode several types of gene products that include lysosomal enzymes, soluble lysosomal proteins, transmembrane domain-containing proteins, and other proteins with different subcellular localizations. ${ }^{1,41}$ The precise localization and function of many of these proteins remain elusive. However, several roles of these proteins have now been elucidated, including apoptosis and autophagy, endocytosis, vesicular trafficking, cell proliferation, $\mathrm{pH}$ homeostasis, synaptic functioning, and protein secretion. ${ }^{1,41}$ Furthermore, researchers ${ }^{42}$ have demonstrated interaction among NCL proteins, with the CLN5 protein interacting with CLN2 and CLN3 polypeptides, suggesting the possibility of common pathways among these subtypes. In a recent study, CLN1, CLN3, CLN6, and CLN8 diseases have been linked to endoplasmic reticulum stress resulting in apoptosis. ${ }^{43}$ Whether the cerebral cortex is particularly susceptible to endoplasmic reticulum stress-related apoptosis accounting for 
predominant cerebral atrophy in these subtypes is unclear but appears plausible. The pathogenesis of NCL is therefore multifactorial and occurs not only due to the accumulation of lipopigments but also due to mitochondrial dysfunction, endoplasmic reticulum stress, and alterations in cellular $\mathrm{pH}$, which lead to excessive production of mitochondrial reactive oxygen species and disturbed calcium homeostasis, resulting in apoptosis and neuronal loss. Each of the NCL proteins has varying effects on these cellular functions, resulting in slight differences in phenotypes and neuroimaging features.

This study has several limitations. First, because it was a retrospective study, MR imaging performed in different machines and protocols was analyzed, with nonuniform imaging parameters. Second, because images were analyzed during a 30-year period, there was an insufficient number of cases with the data required to perform meaningful quantitative analyses. We, therefore, restricted the study to qualitative analysis of signal intensity and volume loss. Third, only 9 patients had follow-up imaging, making it difficult to assess progression of disease. Last, there was under-representation of certain subtypes (eg, CLN3 disease) in this study cohort.

\section{CONCLUSIONS}

CLN1 and CLN7 diseases were the most common subgroups in our study cohort. The difference in the median time from disease onset and diagnosis was 1.5 years. Given recent FDA approval of the use of cerliponase alfa for treatment of CLN2 disease and ongoing phase I/IIa clinical trials with gene therapy for CLN3 and CLN6 diseases, it is imperative to reduce this time gap to arrest disease progression. In patients with a history of developmental regression, brain MR imaging and referral to a neurologist and geneticist are crucial to diagnose patients at the disease onset.

We identified reported classic neuroimaging features in all except 1 patient with NCL in our study, including predominant cerebellar-over-cerebral atrophy in CLN2, CLN5, and CLN7 diseases and minimal abnormality up to early adolescence in CLN3 disease. We confirmed less frequently reported findings of abnormal signal intensity in the deep white matter, posterior limb of the internal capsule, and ventral pons and demonstrated that these findings are more common than previously reported in the literature. We report abnormal signal intensity in the insular/subinsular region for the first time.

\section{ACKNOWLEDGMENTS}

A.B. is partially funded by Ontasian Imaging Laboratory (OIL), Toronto.

Disclosures: Saadet Mercimek-Andrews_UNRELATED: Board Membership: Recordati, BioMarin advisor; Consultancy: Canadian Medical Protective Association expert reviewer, Borden Ladner Gervais expert reviewer; Grants/Grants Pending: Physician Services Incorporation grant*; Payment for Lectures Including Service on Speakers Bureaus: BioMarin, Recordati. Manohar Shroff-RELATED: Other: BioMarin, Comments: I received a one-time honorarium (November 2019) for participating in an afternoon discussion on CLN2 hosted by BioMarin, which manufactures an enzyme-replacement treatment for CLN2. This was 2 months before we started this project. *Money paid to the institution.

\section{REFERENCES}

1. Nita DA, Mole SE, Minassian BA. Neuronal ceroid lipofuscinoses. Epileptic Disord 2016;18:73-88 CrossRef Medline
2. Uvebrant P, Hagberg B. Neuronal ceroid lipofuscinoses in Scandinavia: epidemiology and clinical pictures. Neuropediatrics 1997;28:6-8 CrossRef Medline

3. Mole SE, Williams RE, et al. Neuronal ceroid-lipofuscinoses. In: Adam MP, Ardinger HH, Pagon RA, eds. GeneReviews. University of Washington, Seattle; 1993

4. Geraets RD, Koh Sy, Hastings ML, et al. Moving towards effective therapeutic strategies for neuronal ceroid lipofuscinosis. Orphanet J Rare Dis 2016;11:40 CrossRef Medline

5. Mukherjee AB, Appu AP, Sadhukhan T, et al. Emerging new roles of the lysosome and neuronal ceroid lipofuscinoses. Mol Neurodegener 2019;14:4 CrossRef Medline

6. Kline RA, Wishart TM, Mills K, et al. Applying modern Omic technologies to the neuronal ceroid lipofuscinoses. Biochim Biophys Acta Mol Basis Dis 2020;1866:165498 CrossRef Medline

7. di Ronza A, Bajaj L, Sharma J, et al. CLN8 is an endoplasmic reticulum cargo receptor that regulates lysosome biogenesis. Nat Cell Biol 2018;20:1370-77 CrossRef Medline

8. Cooper JD, Mole SE. Future perspectives: what lies ahead for neuronal ceroid lipofuscinosis research? Biochim Biophys Acta Mol Basis Dis 2020;866:165681 CrossRef Medline

9. Kohlschütter A, Schulz A, Bartsch U, et al. Current and emerging treatment strategies for neuronal ceroid lipofuscinoses. CNS Drugs 2019;33:315-25 CrossRef Medline

10. Gene Therapy for Children with CLN3 Batten Disease. ClinicalTrials. gov. Accessed May 7, 2020

11. Gene Therapy for Children with Variant Late Infantile Neuronal Ceroid Lipofuscinosis 6 (vLINCL6). ClinicalTrials.gov. Accessed May 7, 2020

12. D'Incerti L. MRI in neuronal ceroid lipofuscinosis. Neurol Sci 2000;21:S71-73 CrossRef Medline

13. Baker EH, Levin SW, Zhang Z, et al. MRI brain volume measurements in infantile neuronal ceroid lipofuscinosis. AJNR Am J Neuroradiol 2017;38:376-82 CrossRef Medline

14. Vanhanen SL, Raininko R, Santavuor P, et al. MRI evaluation of the brain in infantile neuronal ceroid-lipofuscinosis, Part 1: postmortem MRI with histopathologic correlation. J Child Neurol 1995;10:438-43 CrossRef Medline

15. Jiangxi X, Li G, Yuanchun Z, et al. MRI findings in childhood with neuronal ceroid lipofuscinosis. Chinese Journal of Radiology 2003;37:802-04

16. Peña JA, Cruz EM, Leendertz R, et al. MRI and proton spectroscopy in children with late infantile neuronal ceroid lipofuscinosis: preliminary results. J Pediatr Neurol 2015;05:215-20 CrossRef

17. Jadav RH, Sinha S, Yasha TC, et al. Magnetic resonance imaging in neuronal ceroid lipofuscinosis and its subtypes. Neuroradiol $J$ 2012;25:755-61 CrossRef Medline

18. Vanhanen SL, Raininko R, Autti T, et al. MRI evaluation of the brain in infantile neuronal ceroid-lipofuscinosis, Part 2: MRI findings in 21 patients. J Child Neurol 1995;10:444-50 CrossRef Medline

19. Autti T, Raininko R, Vanhanen SL, et al. MRI of neuronal ceroid lipofuscinosis. I: cranial MRI of 30 patients with juvenile neuronal ceroid lipofuscinosis. Neuroradiology 1996;38:476-82 CrossRef

20. Vanhanen SL, Puranen J, Autti T, et al. Neuroradiological findings (MRS, MRI, SPECT) in infantile neuronal ceroid-lipofuscinosis (infantile CLN1) at different stages of the disease. Neuropediatrics 2004;35:27-35 CrossRef Medline

21. Dyke J, Sondhi D, Voss $\mathrm{H}$, et al. Brain region specific degeneration with disease progression in late infantile neuronal ceroid lipofuscinosis (CLN2 disease). AJNR Am J Neuroradiol 2016;37:1160-69 CrossRef Medline

22. Roine U, Roine TJ, Hakkarainen A, et al. Global and widespread local white matter abnormalities in juvenile neuronal ceroid lipofuscinosis. AJNR Am J Neuroradiol 2018;39:1349-54 CrossRef Medline

23. Holmberg V, Lauronen L, Autti T, et al. Phenotype-genotype correlation in eight patients with Finnish variant late infantile NCL (CLN5). Neurology 2000;55:579-81 CrossRef Medline 
24. Autti T, Hämäläinen J, Aberg L, et al. Thalami and corona radiata in juvenile NCL (CLN3): a voxel-based morphometric study. Eur J Neurol 2007;14:447-50 CrossRef Medline

25. Tokola AM, Salli EK, Åberg LE, et al. Hippocampal volumes in juvenile neuronal ceroid lipofuscinosis: a longitudinal magnetic resonance imaging study. Pediatr Neurol 2014;50:158-63 CrossRef Medline

26. Lauronen L, Santavuori P, Hirvasniemi A, et al. Northern epilepsy syndrome (NES, CLN8): MRI and electrophysiological studies. Eur J Paediatr Neurol 2001;5(Suppl A):167-73 CrossRef Medline

27. Alkhars FZ, Bo Ali AY, Almohanna MA, et al. Neuronal ceroid lipofuscinoses type 8: expanding genotype/phenotype diversity-first report from Saudi Arabia. Neurosciences (Riyadh) 2020;25:65-69 CrossRef Medline

28. Doccini S, Sartori S, Maeser S, et al. Early infantile neuronal ceroid lipofuscinosis (CLN10 disease) associated with a novel mutation in CTSD. J Neurol 2016;263:1029-32 CrossRef Medline

29. Varvagiannis $\mathrm{K}$, Hanquinet $\mathrm{S}$, Billieux $\mathrm{MH}$, et al. Congenital neuronal ceroid lipofuscinosis with a novel CTSD gene mutation: a rare cause of neonatal-onset neurodegenerative disorder. Neuropediatrics 2018;49:15053 CrossRef Medline

30. Kamate M, Detroja M, Hattiholi V. Neuronal ceroid lipofuscinosis type-11 in an adolescent. Brain Dev 2019;41:542-45 CrossRef Medline

31. Di Fabio R, Colonnese C, Santorelli FM, et al. Brain imaging in Kufs disease type B: case reports. BMC Neurol 2015;15:102 CrossRef Medline

32. Jilani A, Matviychuk D, Blaser S, et al. High diagnostic yield of direct Sanger sequencing in the diagnosis of neuronal ceroid lipofuscinoses. JIMD Rep 2019;50:20-30 CrossRef Medline

33. Machen BC, Williams JP, Lum GB, et al. Magnetic resonance imaging in neuronal ceroid lipofuscinosis. J Comput Tomogr 1987;11:160-66 CrossRef Medline
34. Valavanis A, Friede RL, Schubiger O, et al. Computed tomography in neuronal ceroid lipofuscinosis. Neuroradiology 1980;19:35-38 CrossRef Medline

35. Vanhanen SL, Raininko R, Santavuori P. Early differential diagnosis of infantile neuronal ceroid lipofuscinosis, Rett syndrome, and Krabbe disease by CT and MR. AJNR Am J Neuroradiol 1994;15:1443-53 Medline

36. Haltia M, Rapola J, Santavuori P. Infantile type of so-called neuronal ceroid-lipofuscinosis. histological and electron microscopic studies. Acta Neuropathol 1973;26:157-70 CrossRef Medline

37. Haltia M, Rapola J, Santavuori P, et al. Infantile type of so-called neuronal ceroid-lipofuscinosis, Part 2: morphological and biochemical studies. J Neurol Sci 1973;18:269-85 CrossRef

38. Heiskala H, Gutteridge JM, Westermarck T, et al. Bleomycin-detectable iron and phenanthroline-detectable copper in the cerebrospinal fluid of patients with neuronal ceroid-lipofuscinoses. Am J Med Genet Suppl 1988;5:193-202 CrossRef Medline

39. Wisniewski KE, Kida E, Connell F, et al. New subform of the late infantile form of neuronal ceroid lipofuscinosis. Neuropediatrics 1993;24:155-63 CrossRef Medline

40. Autti T, Raininko R, Launes J, et al. Jansky-Bielschowsky variant disease: CT, MRI, and SPECT findings. Pediatr Neurol 1992;8:121-26 CrossRef Medline

41. McLaren MD, Mathavarajah S, Huber RJ. Recent insights into NCL protein function using the model organism Dictyostelium discoideum. Cells 2019;8:115 CrossRef Medline

42. Vesa J, Chin MH, Oelgeschläger K, et al. Neuronal ceroid lipofuscinoses are connected at molecular level: interaction of CLN5 protein with CLN2 and CLN3. Mol Biol Cell 2002;13:2410-20 CrossRef Medline

43. Marotta D, Tinelli E, Mole SE. NCLs and ER: a stressful relationship. Biochim Biophys Acta Mol Basis Dis 2017;1863:1273-81 CrossRef Medline 